\title{
A reversible cardiomyopathy caused by a high dose of doxylamine intoxication: A case report
}

\author{
DukHee Lee ${ }^{1 *}$ and Eun $\mathrm{Kim}^{2}$ \\ ${ }^{1}$ Department of Emergency Medicine, Ewha Womans University, Mok-dong Hospital, South Korea \\ ${ }^{2}$ Department of Emergency Medicine, Ewha Womans University, Seoul, Korea
}

\begin{abstract}
Doxylamine succinate is a first-generation H1-antihistamine drug that is generally used as a sedative. A 29-year-old woman was admitted to the ED with changes in her mental behavior. She had intentionally taken $5000 \mathrm{mg}(96 \mathrm{mg} / \mathrm{kg})$ of doxylamine. The vital signs at the time were admission were as follows: blood pressure, 128/67 mmHg; pulse, 140 beats/min; respiration, 20 breaths/min; body temperature, $36.0^{\circ} \mathrm{C}$; and $\mathrm{SpO} 28 \%$ given $10 \mathrm{~L} / \mathrm{min}$ oxygen mask. On admission, she showed generalized tonic-clonic seizure in ED. The electrocardiogram (EKG) showed paroxysmal supraventricular tachycardia. Subsequently, the patient's EKG showed wide QRS rhythm with QTc prolonged to $542 \mathrm{~ms}$ and intermittently showed arrhythmia and wide fluctuation in blood pressure. Portable transthoracic echocardiography (TTE) revealed $36 \%$ of left ventricular ejection fraction with global hypokinesia. Due to persistent and varying arrhythmia, fluctuating blood pressure, and intermittent seizures, CVVHDF was initiated. After CVVHDF for 37 hours, her EKG was normalized. The left ventricular ejection fraction improved from $36 \%$ to $64 \%$ and there was no regional wall motion abnormality on her $10^{\text {th }}$ day of hospital stay.
\end{abstract}

The present case suggests that under a scenario of doxylamine overdose of more than $90 \mathrm{mg} / \mathrm{kg}$, emergency physician careful considerate cardiac problems and renal replacement therapy to remove toxic substances.

\section{Introduction}

Doxylamine succinate is a first-generation $\mathrm{H1}$-antihistamine drug that is generally used as a sedative. In urban emergency department (ED) in Korea, doxylamine overdose accounts for $25 \%$ of the visits because of drug overdose [1]. Doxylamine overdose has both peripheral and central anticholinergic effects including tachycardia, confusion, disorientation, seizure, and cardiotoxicity [2]. The present case is about a patient with a high dose of doxylamine intoxication who presented seizures, rhabdomyolysis, and severe cardiotoxicity at the time of admission and was successfully treated with continuous venovenous haemodiafiltration (CVVHDF).

\section{Case report}

A 29-year-old woman was admitted to the ED with changes in her mental behavior. She had no medical and family history. She had intentionally taken $5000 \mathrm{mg}(96 \mathrm{mg} / \mathrm{kg})$ of doxylamine and was transferred to ED 2 hours after drug ingestion. She showed a generalized tonic-clonic seizure twice while being transferred to the hospital. Her Glasgow coma scale was 9. The vital signs were as follows: blood pressure, 128/67 mmHg; pulse, 140 beats/min; respirations, 20 breaths $/ \mathrm{min}$; body temperature, $36.0^{\circ} \mathrm{C}$; and $\mathrm{SpO}_{2} 88 \%$ given $10 \mathrm{~L} / \mathrm{min}$ oxygen mask. At the time of admission, she showed generalized tonicclonic seizure in ED. After stabilization seizure with $4 \mathrm{mg}$ of lorazepam twice, and $250 \mathrm{mg}$ of phenytoin via intravenous, endotracheal intubation was performed. Later, the electrocardiogram (EKG) showed paroxysmal supraventricular tachycardia. After $300 \mathrm{mg}$ of amiodarone administration, the rhythm was converted. The initial arterial blood gas analysis (ABGA) revealed $\mathrm{pH} 6.769, \mathrm{pCO}_{2} 46.0 \mathrm{mmHg}, \mathrm{pO}_{2} 75 \mathrm{mmHg}$, bicarbonate $8 \mathrm{mmol} / \mathrm{L}$, base excess -28 , and saturation $74.0 \%$ (Table 1 ).

The patient was moved to the intensive care unit with conservative treatment. Ten hours after admission, the patient's EKG showed wide
QRS rhythm with QTc prolonged to 542ms, intermittent arrhythmia and wide fluctuation in blood pressure (Figure 1). On emergency cardiologist consultation, portable transthoracic echocardiography (TTE) revealed $36 \%$ of left ventricular ejection fraction with global hypokinesia. Based on the presence of persistent and varying arrhythmia, fluctuating blood pressure, and intermittent seizures, CVVHDF was initiated. CVVHDF was performed through a dual lumen femoral catheter using the Prismaflex ${ }^{\circledR}$ dialysis device with a blood flow of $100 \mathrm{~mL} / \mathrm{h}$ and dialysate flow rate of $1,000 \mathrm{~mL} / \mathrm{h}$ with a biocompatible AN69 membrane (Gambro, Meyzieu, France) with $1 \mathrm{~m}^{2}$ filter at the time of initiation of treatment. After CVVHDF for 37 hours, her EKG was normalized and no seizure activity was noted. Electroencephalogram showed bi-synchronous diffuse slow waves with frontal dominance on her $7^{\text {th }}$ day of hospital stay and she became alert on the $8^{\text {th }}$ day.

A follow-up TTE showed improvement in the left ventricular ejection fraction from $36 \%$ to $64 \%$ with no regional wall motion abnormality on her $10^{\text {th }}$ day of hospital stay. She was discharged without any signs of complications.

\section{Discussion}

Doxylamine is a member of the ethanolamine class of antihistamine which is available as an over-the-counter sleep-inducing agent [3].

${ }^{\star}$ Correspondence to: DukHee Lee, Department of Emergency Medicine, Ewha Womans University, Mok-dong Hospital, Mok-dong 911-1, Yang-ChoenKu, Seoul 07985, South Korea, E-mail: calla521@empas.com

Key words: doxylamine, continuous venovenous haemodiafiltration, cardiomyopathy

Received: October 11, 2019; Accepted: October 22, 2019; Published: October 25,2019 
Table 1. Laboratory findings and clinical management

\begin{tabular}{|c|c|c|c|c|c|c|c|c|c|c|c|c|}
\hline Time (hours)* & 2 & 11 & 24 & 33 & 43 & 48 & 57 & 80 & 104 & 128 & 152 & 176 \\
\hline pH & 6.769 & 7.499 & 7.421 & 7.403 & 7.426 & 7.417 & 7.399 & 7.408 & 7.421 & 7.520 & 7.475 & 7.405 \\
\hline $\mathrm{pCO}_{2}$ (Torr) & 46.0 & 40.1 & 35.5 & 39 & 37.3 & 40.8 & 38.7 & 43.6 & 39.8 & 34.4 & 38.2 & 35.5 \\
\hline $\mathrm{pO}_{2}$ (Torr) & 75 & 122.0 & 120.0 & 120 & 109.2 & 107.5 & 99.2 & 83.3 & 107.2 & 103.4 & 101.6 & $99 . .3$ \\
\hline Bicarbonate (mmol/L) & 6.7 & 28.2 & 22.6 & 24.4 & 24 & 25.7 & 23.4 & 26.9 & 25.3 & 27.5 & 27.5 & 17.5 \\
\hline Lactic acid (mg/dL) & 208 & 22.1 & 18.9 & 10.4 & 10.4 & 12.3 & 12.0 & 10.5 & 8.1 & 7.6 & 5.8 & 3.8 \\
\hline Anion gap (mEq/L) & 35.3 & 7.8 & 11.4 & 9.6 & 10 & 7.3 & 8.6 & 6.1 & 6.7 & 7.5 & 6.5 & 6.0 \\
\hline CPK(IU/L) & 83 & 568 & 1700 & 2806 & 2403 & 2600 & 5368 & 11951 & 16240 & 16790 & 14120 & 7650 \\
\hline Creatinine (mg/dL) & 0.98 & 0.73 & $0.57-$ & 0.47 & 0.6 & 0.45 & 0.52 & 0.57 & 0.49 & 0.52 & 0.57 & 0.53 \\
\hline Urine pH & 5.5 & 8.5 & 8.0 & 8.0 & 8.5 & 7.5 & 7.5 & 7.0 & 7.5 & 8.0 & 8.5 & 8.0 \\
\hline WBC $\left(\right.$ per $\left.\mathbf{m m}^{3}\right)$ & 21030 & 13520 & & 20920 & 16620 & 14060 & 15500 & 16940 & 144400 & 9070 & 1190 & 5380 \\
\hline Clinical course $\&$ treatment & Intubation & $\begin{array}{c}\text { CVVHDF } \\
\text { start }\end{array}$ & & & & $\begin{array}{c}\text { CVVHDF } \\
\text { removal }\end{array}$ & & Extubated & & & & Discharged \\
\hline
\end{tabular}

$\mathrm{WBC}=$ white blood cell count

*Time 0 represents the time of ingestion of doxylamine

$\dagger$ Continuous venovenous haemodiafiltration (CVVHDF) was started at 11 hours after ingestion of doxylamine and stopped at 41 hours.

\$Final laboratory results at the time of discharge from the hospital.
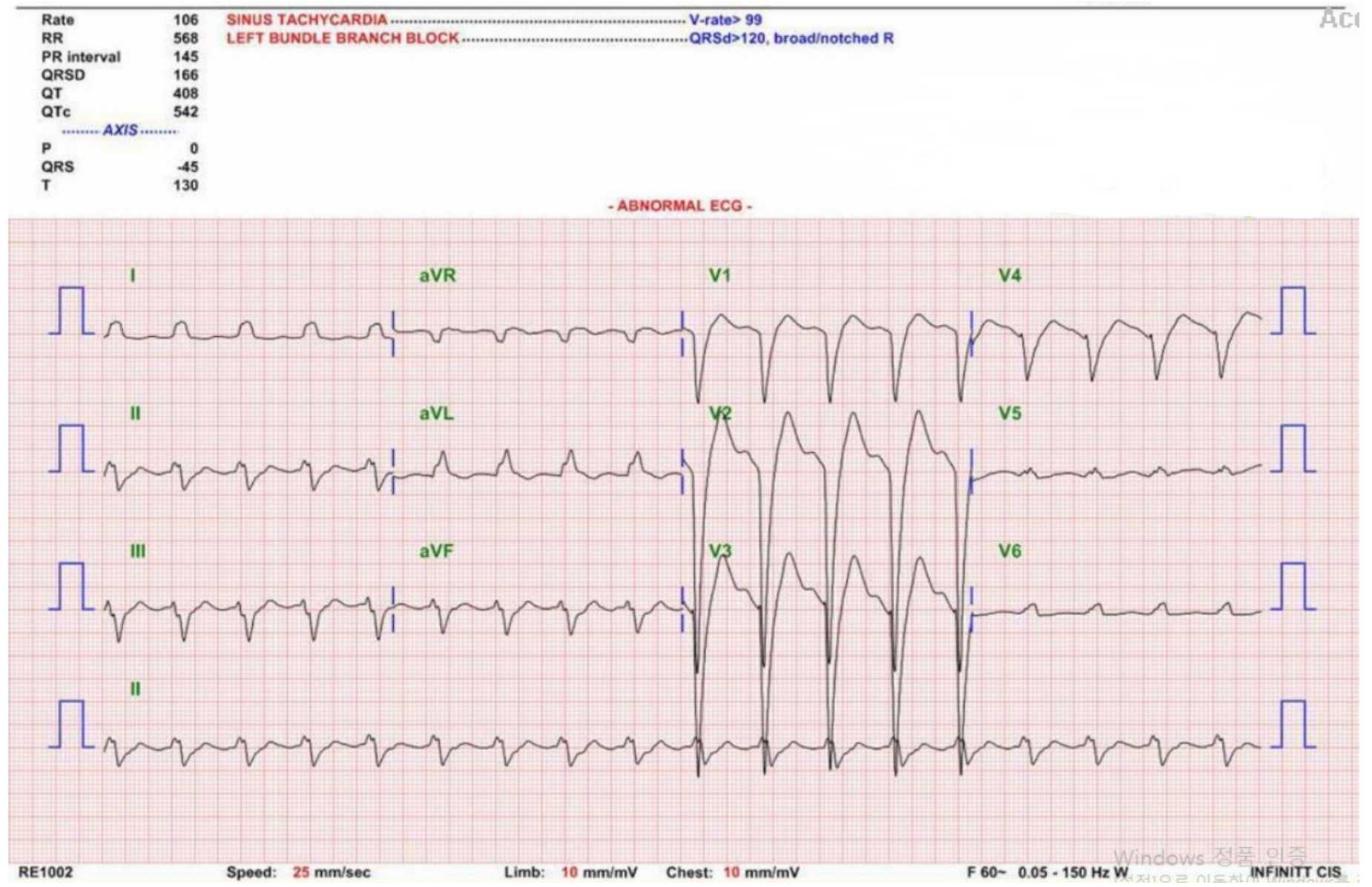

Figure 1. Electrocardiography with wide QRS rhythm with QTc prolonged to $542 \mathrm{~ms}$

Doxylamine reaches a peak plasma concentration in $2 \sim 3$ hours and has a half-life of 10 11 hours. However, the toxic doses and pharmacokinetics are not well defined. Clinical manifestations of doxylamine overdose patients include drowsiness, seizures as a neurologic symptom, sinus tachycardia, hypotension as a cardiovascular symptom, and rhabdomyolysis [2].

In this case, the patient suffered from various complications of antihistamine overdose. She showed seizure, confused mentality, and cardiac arrhythmia. Conservative treatment with intubation, aggressive hydration, antiarrhythmic drugs, and urine alkalinization was performed. Even though metabolic acidosis was corrected, a decrease in anion gaps was observed without any occurrence of severe rhabdomyolysis. Presence of arrhythmias, severe hypotension, and cardiomyopathy was observed in TEE within 10 hours after ingestion.

Poluzzi E, et al. have reported pro-arrhythmic potential of oral antihistamine. A few second-generation antihistamines have been reported to be associated with the signal of torsadogenicity. However, few reports state the weak signal of doxylamine lowered a number of 
absolute cases of arrhythmia [4]. In the present case, the patient showed paroxysmal supraventricular tachycardia, wide QRS rhythms with QTc prolonged and severe cardiomyopathy.

Conservative treatment as massive hydration and urine alkalization is the typical treatment for doxylamine overdose. Furthermore, renal replacement therapy is needed in cases of renal failure [5]. The present patient had normal creatinine level, but the toxic effect was severe. Thus, she underwent CVVHDF for 37 hours for the removal of toxic substances from the body and the results showed normalized EKG and improvement in her heart function.

There are case reports that doxylamine causes rhabdomyolysis $[3,6]$. The present case revealed the development of cardiomyopathy. Cardiomyopathy associated with doxylamine is a rare complication. Development of cardiomyopathy is associated with dose and exposure time. It was not possible to measure the blood level of doxylamine due to lack of appropriate measurement systems in the hospitals in Korea.

The present case suggests that if an overdose of doxylamine is more than $90 \mathrm{mg} / \mathrm{kg}$, careful consideration of cardiac problems is needed. Thus, it is important to focus on electrocardiography and echocardiogram to suspect any cardiotoxicity caused due to antihistamine overdose, and renal replacement therapy should be considered for the removal of toxic substances.

\section{References}

1. Kim HJ, Oh SH, Youn CS, Wee JH, Kim JH, et al. (2011) The associative factors of delayed-onset rhabdomyolysis in patients with doxylamine overdose. Am J Emerg Med 29: 903-907.

2. Hoffman RS, Howland MA, Lewin NA, Nelson LS, Goldfrank LR (2015) Antihistamines and decongestants. In: Goldfrank's toxicologic emergency [10th Edn], Mc Graw Hill. P: 660-676.

3. Syed H, Som S, Khan N, Faltas W (2009) Doxylamine toxicity: Seizure, rhabdomyolysis and false positive urine drug screen for methadone. BMJ Case Rep 2009: bcr09.2008.0879. [Crossref]

4. Poluzzi E, Raschi E, Godman B, Koci A, Moretti U, et al. (2015) Pro-arrhythmic potential of oral antihistamines (H1): Combining adverse event reports with drug utilization data across europe. PLoS One 10: e0119551. [Crossref]

5. Kim E, Choi YH, Lim JY, Lee J, Lee DH (2017) The effect of early urine alkalinization on occurrence rhabdomyolysis and hospital stay in high dose doxylamine ingestion. Am J Emerg Med 36: 1170.

6. Hampel G, Horstkotte H, Rumpf KW (1983) Myoglobinuric renal failure due to druginduced rhabdomyolysis. Hum Toxicol 2: 197-203. [Crossref]

Copyright: (C2019 Lee D. This is an open-access article distributed under the terms of the Creative Commons Attribution License, which permits unrestricted use, distribution, and reproduction in any medium, provided the original author and source are credited. 